\title{
Complicated adult right-sided Bochdalek hernia with Chilaiditi's syndrome: a case report
}

\author{
Motonobu Watanabe ${ }^{1,2,3^{*}}$, Osamu Ishibashi ${ }^{2}$, Muneaki Watanabe ${ }^{2}$, Tadashi Kondo ${ }^{1,2}$ and Nobuhiro Ohkohchi ${ }^{1}$
}

\begin{abstract}
An extremely rare adult case that underwent surgery for ileus caused by Bochdalek hernia associated with Chilaiditi's syndrome is presented. A 65-year-old woman complaining of upper abdominal pain presented to our hospital. Abdominal plain radiography showed increased intestinal gas, and computed tomography $(C T)$ showed the transverse colon located above the right lobe of the liver, representing Chilaiditi's sign. She was diagnosed as having ileus and treated with decompression therapy by a nasoenteric tube. After hospitalization, the patient developed dyspnea, and $C T$ showed intestinal herniation into the right thoracic cavity. She was diagnosed as having strangulated ileus caused by Bochdalek hernia. An emergent laparotomy was performed, and it showed a hole of $5 \mathrm{~cm}$ in diameter at the right hemi-diaphragm. The transverse colon was incarcerated through the hole, it was pulled back to the abdominal cavity, and a right hemicolectomy was performed because of necrotic changes. A small part of the liver was also herniated into the right thoracic cavity, and it was returned to the abdominal cavity. The defect in the diaphragm was closed by direct suture. Although the patient developed an abscess in the thoracic cavity postoperatively, she improved with antibiotic therapy and was discharged 2 months after the operation.
\end{abstract}

Keywords: Bochdalek hernia; Chilaiditi's syndrome; Strangulated ileus; In adults

\section{Background}

Bochdalek hernia is one of the most common congenital diaphragmatic hernias, and most cases are diagnosed in the neonatal period with clinical features related to the respiratory system [1]. In contrast, symptoms are rare in adults, and it is usually incidentally discovered in patients with gastrointestinal symptoms [2]. Chilaiditi's sign is also a rare radiographic finding of subdiaphragmatic radiolucency due to interposition of the intestine between the liver and the diaphragm, and when it is associated with digestive symptoms, it is termed Chilaiditi's syndrome [3, 4]. In both Bochdalek hernia and Chilaiditi's Syndrome, if the symptoms progress to bowel obstruction or ischemia, emergent surgical treatment is needed. In this paper, an extremely rare

\footnotetext{
* Correspondence: motowide@aol.com

'Department of Surgery, Graduate School of Comprehensive Human

Sciences, University of Tsukuba, 1-1-1 Tennoudai, Tsukuba, Ibaraki 305-8558,

Japan

${ }^{2}$ Department of Surgery, Mito Kyodo General Hospital, 3-2-7 Miyamachi, Mito,

Ibaraki 310-0015, Japan

Full list of author information is available at the end of the article
}

adult case that underwent surgery for ileus caused by a Bochdalek hernia associated with Chilaiditi's syndrome is presented.

\section{Case presentation}

A 65-year-old woman visited our hospital with a complaint of continuous upper abdominal pain. She had a medical history of rheumatoid arthritis and was on prednisolone $5 \mathrm{mg}$ a day. On admission, she was afebrile and had no abdominal distention, but she had tenderness over the whole abdomen, and her bowel sounds were slightly decreased. Apart from minimal hypokalemia, her laboratory values were normal. Abdominal X-ray showed small intestinal gas and the computed tomography showed the transverse colon located above the right lobe of the liver, known as Chilaiditi's sign (Fig. 1a). A small part of the liver and intestinal fat tissue had also been seen in the bottom of the right thoracic cavity, probably due to the congenital hernia (Fig. 1b, c). She was diagnosed as having ileus due to Chilaiditi's syndrome and was treated with decompression therapy by a nasoenteric tube. Four days

\section{实 Springer}



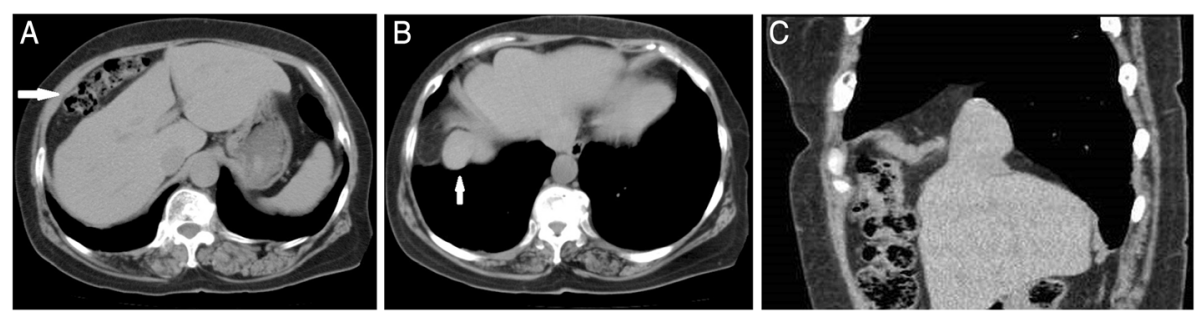

Fig. 1 a Computed tomography (CT) of the abdomen showing the transverse colon located above the right lobe of the liver (arrow). $\mathbf{b} \subset T$ showing a small part of the liver herniated into the right thoracic cavity (arrow). c Sagittal view of the same CT showing a small part of the liver and intestinal fat tissue in the right thoracic cavity

later, she developed dyspnea and her abdominal pain worsened. Laboratory examination showed elevations in the white blood cell count $(10,900 / \mu \mathrm{l})$, C-reactive protein (19.48 $\mathrm{mg} / \mathrm{dl})$, fibrin/fibrinogen degradation products (FDP) $(12.1 \mu \mathrm{g} / \mathrm{ml})$, aspartate aminotransferase (AST) (43 $\mathrm{U} / \mathrm{l})$, and alanine aminotransferase (ALT) (43 U/l). Chestabdominal computed tomography (CT) showed intestinal incarceration in the right thoracic cavity (Fig. 2). With these findings, the patient was diagnosed as having incarceration due to a right Bochdalek hernia and Chilaiditi's syndrome.

Exploratory laparotomy was performed, and it showed a hole of $5 \mathrm{~cm}$ in diameter at the right hemi-diaphragm (Fig. 3a). The transverse colon was herniated into the right thoracic cavity through the hole. A small part of the right lobe of the liver was also herniated into the cavity and adhered to the bottom lobe of the right lung. The transverse colon was pulled back into the abdominal cavity, but a right hemicolectomy was performed because the incarcerated part had developed necrosis and showed micro perforation (Fig. 3b). The herniated part of the liver was separated from the lung and returned to the abdominal cavity (Fig. 3c). The diaphragmatic defect was closed by direct suture with 1-0 absorbable thread, and drains were placed into the right thoracic cavity and right subphrenic space. The patient developed an abscess in the right thoracic cavity after removal of the chest drain postoperatively (Fig. 4a), and she was treated with systemic antibiotics. The abscess resolved with treatments (Fig. 4b), and she was discharged 2 months after the operation. As of 56 months after the surgery, she is doing well without recurrence of any symptoms.

\section{Discussion}

Chilaiditi's sign is a rare radiological finding of segmental interposition of the colon between the liver and the diaphragm. Chilaiditi's syndrome refers to a clinically symptomatic patient with radiographic findings; the syndrome was first described by Demetrius Chilaiditi in 1910 [3]. Chilaiditi's sign has been reported in association with various conditions, such as liver cirrhosis, segmental agenesis of the liver, relaxation of the suspensory ligament, and hypermobile colon with long mesentery, constipation, multiple pregnancies, obesity, and significant weight loss [4]. Although the condition is usually

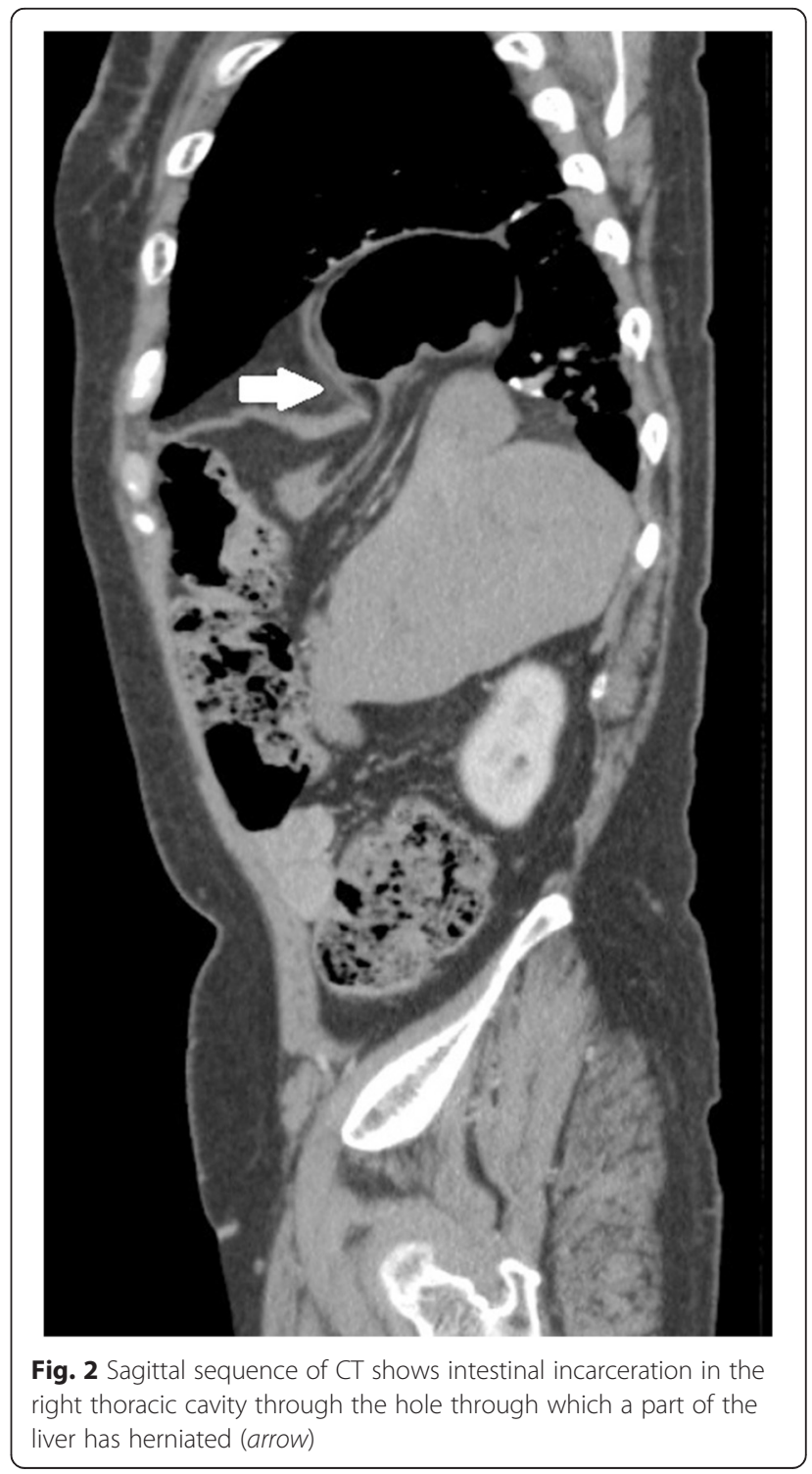



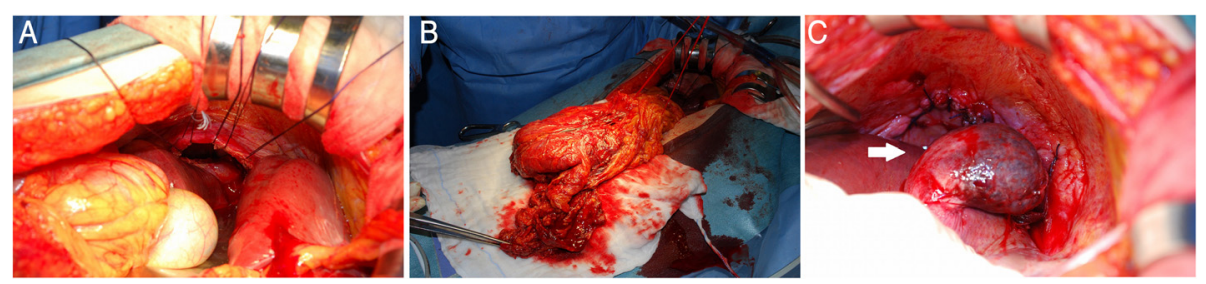

Fig. 3 a Intraoperative photographs showing a hole of $5 \mathrm{~cm}$ in diameter at the right hemi-diaphragm. $\mathbf{b}$ The part of the transverse colon that was pulled back into the abdominal cavity from the right thoracic cavity. c A part of the right lobe of the liver that was returned to the abdominal cavity from the thoracic cavity (arrow). This part of the liver adhered to the bottom lobe of the right lung. It was separated from the lung and returned to the abdominal cavity

asymptomatic and found incidentally, it sometimes occurs with abdominal pain, distention, vomiting, constipation, and obstruction. Treatment is usually conservative, but if the symptoms progress to mechanical bowel obstruction and bowel ischemia, surgical treatment is needed $[5,6]$.

Congenital hernias of the diaphragm can be classified into four different types: eventration of the diaphragm, posterolateral hernia of Bochdalek, parasternal hernia of Morgagni-Larrey, and peritoneopericardial hernia [7]. A Bochdalek diaphragmatic hernia is one of the most common congenital diaphragmatic hernias in infants and can result in severe respiratory distress, necessitating immediate surgery. In contrast, its presentation in adulthood is rare, and it is usually discovered incidentally in patients presenting with gastrointestinal symptoms $[2,8]$. Most of the hernias are found on the left side, and right-sided hernias are rarer because the right pleuroperitoneal canal closes earlier and the liver buttresses the right diaphragm [9]. Fewer than 200 cases of adult Bochdalek hernia have been reported, with even fewer right-sided hernias in adults [8]. Moreover, a literature search using the term 'Bochdalek hernia' in combination with 'right-sided' and 'colon' and 'adult' returned only 11 cases, in addition to the present case [1,9-18].

In the present case, at the time of admission, abdominal CT showed the transverse colon located above the right lobe of the liver, representing Chilaiditi's sign. Furthermore, intestinal fat tissue and a part of the liver were also herniated into the right thoracic cavity, probably due to the Bochdalek hernia. After hospitalization, the patient gradually developed dyspnea, and CT showed intestinal herniation into the right thoracic cavity. These findings indicate that the increased intraperitoneal pressure due to ileus induced incarceration of the colon into the thoracic cavity through the defect next to the herniated liver. Although an emergent laparotomy was performed, a right hemicolectomy was needed because of necrotic changes.

Most Bochdalek hernias are treated surgically with thoracotomy or laparotomy, and several cases of thoracoscopic and laparoscopic repairs have recently been reported. The transthoracic approach enables direct observation of the herniated viscera, and the hilum of the hernia or sac, and allows easy removal of the herniated viscera. The transperitoneal approach also allows confirmation of the position of the viscera and easy repairs [2]. However, in difficult cases such as the present case, the open transperitoneal approach is preferable to achieve emergent release of the incarceration and repair of the damaged viscera.

The diaphragmatic defect is repaired by primary closure or with a prosthetic mesh or muscle flap. Primary repair is performed when there is sufficient diaphragm to close without tension, and non-absorbable thread is usually used to close the defect to avoid recurrence. Prosthetic mesh has been used to repair large congenital diaphragmatic hernias, but it should not be used in contaminated situations $[8,19]$. In the present patient, there
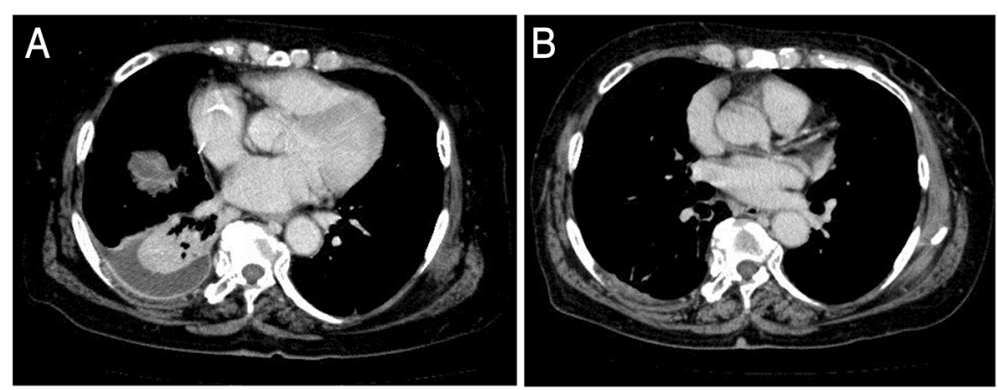

Fig. 4 a Two-week postoperative chest-abdominal CT shows an abscess in the right thoracic cavity. b Six-week postoperative CT shows disappearance of the abscess in the right thoracic cavity 
was sufficient diaphragm for direct closure without tension, and absorbable thread was used to minimize the risk of infection postoperatively as it was a contaminated case. The patient has had no recurrence of hernia for 56 months after the operation, and further follow-up is needed.

\section{Conclusions}

An extremely rare case of a right-sided Bochdalek hernia associated with Chilaiditi's syndrome in an adult who was treated via laparotomy was described. Chilaiditi's sign and Bochdalek hernia are usually asymptomatic, and the disorder may manifest eventually. Symptoms and clinical status may vary from mild to severe, so clinicians should consider this disorder in their daily examinations and treat such cases appropriately to avoid complications.

\section{Consent}

Written informed consent was obtained from the patient for publication of this case report and accompanying images. A copy of the written consent is available for review by the Editor-in-Chief of this journal.

\section{Abbreviations}

ALT: alanine aminotransferase; AST: aspartate aminotransferase;

CT: computed tomography; FDP: fibrin/fibrinogen degradation products.

\section{Competing interests}

The authors declare that they have no competing interests.

\section{Authors' contribution}

MoW participated fully in the clinical treatment and follow-up of the patient and drafted the manuscript. MoW and OI performed the operation and designed the study. MuW, TK, and NO are members of the attending staff of the department who discussed and provided advice about the treatment. Al authors read and approved the final manuscript.

\section{Author details}

'Department of Surgery, Graduate School of Comprehensive Human Sciences, University of Tsukuba, 1-1-1 Tennoudai, Tsukuba, Ibaraki 305-8558, Japan. ${ }^{2}$ Department of Surgery, Mito Kyodo General Hospital, 3-2-7 Miyamachi, Mito, Ibaraki 310-0015, Japan. ${ }^{3}$ Department of Surgery, Moriya Daiichi General Hospital, 1-17 Matsumaedai, Moriya, Ibaraki 302-0102, Japan.

Received: 28 June 2015 Accepted: 1 October 2015

Published online: 06 October 2015

\section{References}

1. Sinha M, Gibbons P, Kennedy SC, Matthews HR. Colopleural fistula due to strangulated Bochdalek hernia in an adult. Thorax. 1989;44:762-3.

2. Suzuki T, Okamoto T, Hanyu K, Suwa K, Ashizuka S, Yanaga K. Repair of Bochdalek hernia in an adult complicated by abdominal compartment syndrome, gastropleural fistula and pleural empyema: report of a case. Int J Surg Case Rep. 2014;5:82-5

3. Chilaiditi D. Zur Frage der Hepatoptose und Ptose im allgemeinen im Anschluss an drei Fälle von temporärer, partieller Leberverlagerung 1910-1911; 16:173-208

4. AldossI T, Abuzetun JY, Nusair M, Suker M, Porter J. Chilaiditi syndrome complicated by cecal perforation. South Med J. 2009:102:841-3.

5. Haratake N, Yamazaki K, Shikata Y, Haratake N, Yamazaki K, Shikata Y. Diaphragmatic hernia caused by heterotopic endometriosis in Chilaiditi syndrome: report of a case. Surg Today. 2014;45(9):1194-6.
6. Saber AA, Boros MJ. Chilaiditi's syndrome: what should every surgeon know? Am Surg. 2005;71:261-3.

7. Thoman DS, Hui T, Phillips EH. Laparoscopic diaphragmatic hernia repair. Surg Endosc. 2002;16:1345-9.

8. Deb SJ. Massive right-sided Bochdalek hernia with two unusual findings: a case report. J Med Case Rep. 2011:5:519.

9. Laaksonen E, Silvasti S, Hakala T. Right-sided Bochdalek hernia in an adult: a case report. J Med Case Rep. 2009;3:9291.

10. Costa Almeida CE, Reis LS, Almeida CM. Adult right-sided Bochdalek hernia with ileo-cecal appendix: Almeida-Reis hernia. Int J Surg Rep. 2013;4:778-81.

11. Slesser AA, Ribbans H, Blunt D, Stanbridge R, Buchanan GN. A spontaneous adult right-sided Bochdalek hernia containing perforated colon. JRSM Short Rep. 2011;2:54

12. Aqrafiotis AC, Kotzampassakis N, Boudaka W. Complicated right-sided Bochdalek hernia in an adult. Acta Chir Belg. 2011;111:171-3.

13. Fraser JD, Craft RO, Haroid KL, Jaroszewski DE. Minimally invasive repair of a congenital right-sided diaphragmatic hernia in an adult. Surg Laparosc Endosc Percutan Tech. 2009;19:e5-7.

14. Kavanagh DO, Ryan RS, Waldron R. Acute dyspnoea due to an incarcerated right-sided Bochdalek's hernia. Acta Chir Belg. 2008;108:604-6.

15. Rout S, Foo FJ, Hayden JD, Guthrie A, Smith AM. Right-sided Bochdalek hernia obstructing in an adult: case report and review of the literature. Hernia. 2007:11:359-62.

16. Court FG, Wemyss-Holden SA, Maddern GJ. Postoperative colonic perforation in a right-sided congenital diaphragmatic hernia in an adult. Int Surg. 2003;88:9-11.

17. Kanazawa A, Yoshioka Y, Inoi O, Murase J, Kinoshita H. Acute respiratory failure caused by an incarcerated right-sided adult Bochdalek hernia: report of a case. Surg Today. 2002;32:812-5.

18. Sidenius K, Ahlgren L. Right-sided diaphragmatic hernia combined with malformations of the intestinal tract and the liver. Uqeskr Laeger. 1983;145:2852-3

19. Kesieme EB, Kesieme CN. Congenital diaphragmatic hernia: review of current concept in surgical management. ISRN Surg. 2011;2011:974041

\section{Submit your manuscript to a SpringerOpen ${ }^{\circ}$ journal and benefit from:}

- Convenient online submission

- Rigorous peer review

- Immediate publication on acceptance

- Open access: articles freely available online

- High visibility within the field

- Retaining the copyright to your article

Submit your next manuscript at $>$ springeropen.com 